\title{
Design of pH Measuring in Wireless Therapy Capsule Against Helicobacter Pylori Infections
}

\author{
Binbin Ren ${ }^{1, a}$, Haiyan Tan ${ }^{1}$, Binlin Chen ${ }^{1}$, Bin Zheng ${ }^{1}$, Zhangyong $\mathrm{Li}^{1}$ and Wei \\ Wang ${ }^{1}$ \\ ${ }^{1}$ Research Center of Biomedical Engineering, Chongqing University of Posts and \\ Telecommunications, Chongqing, China, 400065. \\ a rbinbme@qq.com
}

Keywords: $\mathrm{pH}$ measuring, wireless therapy capsule, micro controller.

\begin{abstract}
A wireless blue light therapy capsule against Helicobacter Pylori infections based on a $\mathrm{pH}$ sensor was addressed. A pH measuring circuit module and wireless communication module were designed to pre-process and transmit the $\mathrm{pH}$ signal. By measuring the $\mathrm{pH}$ value changes, the capsule can identify the locations and trace the $\mathrm{pH}$ of the gastrointestinal tract. A micro controller was designed to sample the $\mathrm{pH}$ signal and regulate the therapy parameters according the feedback information. Vitro experiments were conducted to show the performances of the $\mathrm{pH}$ sensing module.
\end{abstract}

\section{Introduction}

Helicobacter Pylori (H. pylori) colonizes the mucus layer of the human stomach which causes peptic ulcers and adenocarcinoma [1]. Recently, blue light is widely used in clinic to kill bacteria. It is reported that blue light exhibits bactericidal effects against cultured Helicobacter pylori $(H$. pylori) and many other microbial bacteria around the wavelength of $405 \mathrm{~nm}$ [2-3]. Additional tests indicated that the largest reduction in bacterial load was in the antrum $(>97 \%)$, followed by body $(>95 \%)$ and fundus $(>86 \%)$, with treatments by blue light at wavelength of $408 \mathrm{~nm}[4,5]$. These results proved that blue light could be used to kill the $H$. pylori in clinic to against the $H$. pylori infections.

Advancement in sensor technology and semiconductor technology has prompted highly integrated applications. Endoscopy capsule and physiological parameters detection capsule are just some representatives. As a typical micro medical device, the first endoscopy capsule named M2A provided a noninvasive detection method for digestive tract [6]. Different capsule devices have been designed to suit different purposes in clinical treatments such as non-invasive capsule for targeted drug delivery, capsule robot for local surgery, or monitoring capsule for physiological information collection [7-11]. Combined blue light killing H. pylori with capsule designing, we proposed a blue light therapy capsule based on a $\mathrm{pH}$ sensor to against Helicobacter Pylori infections in this study. And $\mathrm{pH}$ measurement is the key issue in this paper will be discussed. By measuring the $\mathrm{pH}$ value of gastrointestinal tract, it indicates the approximate location of the capsule when it moved along in the digestive tract. For further, the device can mark the places with abnormal $\mathrm{pH}$ value and adjust work parameters with feedback information.

\section{System Design}

System architecture. The inner architecture of the proposed capsule, shown in Figure 1. The $\mathrm{pH}$ measuring unit consists of a $\mathrm{pH}$ sensor and a measuring circuit to detect the $\mathrm{pH}$ value. The $\mathrm{pH}$ sensor measures the changes of voltage that reflects the changes of $\mathrm{pH}$ values. The measuring circuit amplifies the voltage signal from the $\mathrm{pH}$ sensor so that the MCU can acquire the analog voltage signal accurately. 


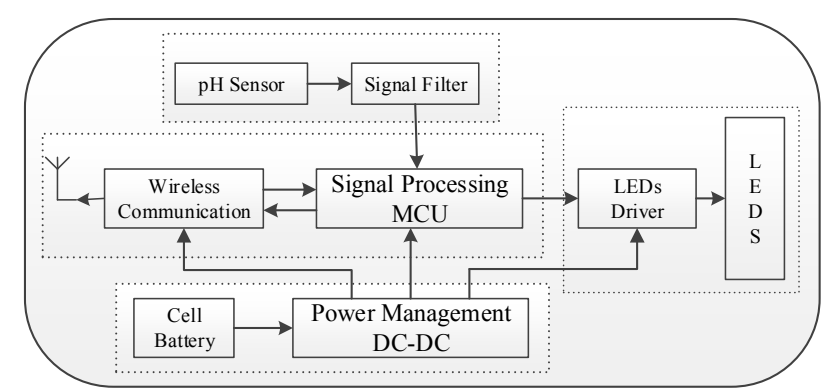

Figure 1. Architecture inside the capsule

$\mathrm{pH}$ Sensor. The $\mathrm{pH}$ values range from 1 to 7.5 for the whole digestive tract with a $\mathrm{pH}$ value about 7 in the esophagus, 1 4 for the gastric juice, and 6.6 7.5 for the intestinal juice [12]. Clearly, the sensor needs to cover the entire $\mathrm{pH}$ range with a resolution less than 2.6. For above considerations, antimony electrode is selected as the $\mathrm{pH}$ sensor whose detection range is from 1 to 9 . The antimony electrode belongs to the class of oxidation-reduction solid electrode which has two electrodes, one for $\mathrm{pH}$ measurement and the other for reference. The change of voltage between the two electrodes is measured, and it scales linearly with the change in $\mathrm{pH}$ value at a fixed ambient temperature. The out voltage formula as follow:

$$
V=V_{0}+\frac{2.303 R T}{F} p H
$$

where $\mathrm{V}$ is measuring voltage, $\mathrm{R}$ for gas constant $8.314, \mathrm{~T}$ as target temperature $(\mathrm{K}), \mathrm{F}$ for faraday constant 96500. According to the formula, measuring voltage increases with the increase of $\mathrm{pH}$ value when the temperature is stable.

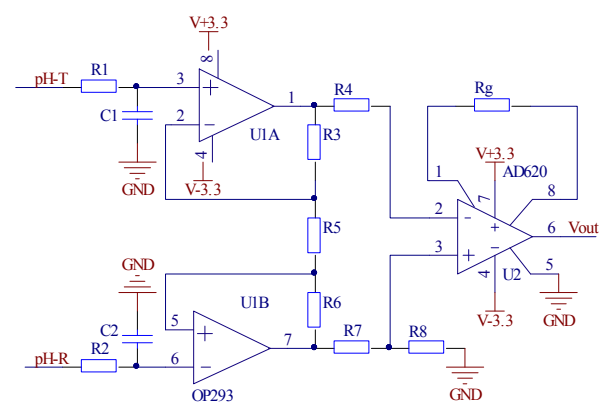

Figure 2. pH Measuring Circuit

$\mathrm{pH}$ Measuring Circuit. The voltage between $\mathrm{pH}$ measuring electrode and reference electrode is the target signal. The voltage changes with the changing of $\mathrm{pH}$ value. Measuring circuit amplifies the voltage and removes noising signal. Impedance circuit filters the signal to a compatible value for micro controller. As shown in Figure 2, voltage follower and subtraction with functions such as isolation, buffering, filtering were constituted by OP293. An amplifier AD620 was employed to amplify the signal with high input resistance and common mode rejection ratio.

System operation. The wireless communication chip nRF24L01 was applied in this system which is a single chip radio transceiver for the worldwide band. The InGaN LED with a wavelength of $408 \pm 2 \mathrm{~nm}$ was employed in it as light source for therapy. MSP430G2553, a low-power-cost and mixed-signal controller with analog-to-digital converter embedded chip was selected as the core component of the MCU module. Firstly, the capsule is turned on when taken out of the magnetic cover and the MCU enters wake-up mode. Then the micro controller samples the $\mathrm{pH}$ value measured by $\mathrm{pH}$ sensor and processes the $\mathrm{pH}$ data to pinpoint the capsule location and turn on LEDs when the capsule moves into the stomach. The micro controller also regulate the light source based on the feedback $\mathrm{pH}$ information and transmit the data outside. When the capsule is out of stomach, the system will turn off.

\section{Experiment Results}

$\mathrm{pH}$ Sensor Time Response. The $\mathrm{pH}$ sensor has a cylinder shape with $3.5 \mathrm{~mm}$ in diameter and $5.5 \mathrm{~mm}$ in length. A series of control experiments are conducted to test the performance of the $\mathrm{pH}$ 
measuring unit. Liquid of different acidity with $\mathrm{pH}$ value ranging from 1 to 8 is prepared with $\mathrm{HCl}$ and $\mathrm{NaOH}$, and then placed in eight vessels labeled as number1 to 8 . The controlled measuring experiments were also conducted by the standard pH meter PB-10 (Sartorius Corporation). Buffer solution with $\mathrm{pH}$ value of 7.2 was prepared to calibrate PB-10 and sensor before each measurement.

\begin{tabular}{|c|c|c|c|c|c|c|c|c|}
\hline \multirow{2}{*}{$\begin{array}{l}\mathrm{pH} \\
\text { time/s }\end{array}$} & 1.1 & 2.3 & 3.2 & 4.3 & 5.1 & 6.2 & 7.4 & 8.6 \\
\hline & \multicolumn{8}{|c|}{ Measuring voltage/mV } \\
\hline 0 & 160 & 213 & 255 & 309 & 331 & 381 & 428 & 469 \\
\hline 90 & 162 & 211 & 256 & 309 & 332 & 378 & 428 & 471 \\
\hline 180 & 161 & 212 & 255 & 308 & 332 & 379 & 427 & 470 \\
\hline
\end{tabular}

$\mathrm{pH}$ Measuring Calibration. Five group comparing experiments were carried out to calibrate the performance of $\mathrm{pH}$ sensor. For each labeled $\mathrm{pH}$ liquid, five experiments were conducted to measure the $\mathrm{pH}$ value and the voltage. To ensure each result was stable, each experiment took about 5 minutes. The average voltage and $\mathrm{pH}$ value over the five replicates were calculated and depicted in Figure 3.

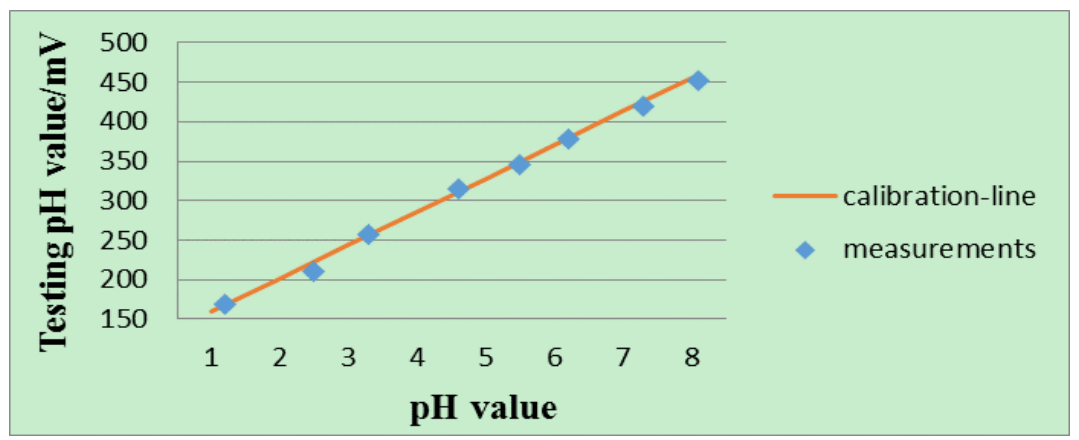

Figure 3. The calibration for the average voltage of $\mathrm{pH}$ measured

According to the vitro experiments, the $\mathrm{pH}$ sensor sensitivity is about $42 \pm 2 \mathrm{mV} / \mathrm{pH}$, and resolution better than 0.2 in $\mathrm{pH}$ value. The $\mathrm{pH}$ value difference between the esophagus and the stomach is about 3 , which corresponds to $126 \mathrm{mV}$ in voltage. Similarly, the $\mathrm{pH}$ value difference between the stomach and the intestinal tract is about 2.6 or $110 \mathrm{mV}$ in voltage. The above two voltage thresholds are the significant parameters for the system to detect the capsule location intelligently. It should be noted that the $\mathrm{pH}$ testing precision is influenced by temperature. The temperature in the stomach of human is $36.7 \pm 0.5^{\circ} \mathrm{C}$, and in the intestinal tract is about $36.9^{\circ} \mathrm{C} \sim 37.9^{\circ} \mathrm{C}$. Both of them are relatively constant $[13-14]$. The change in temperature is small, so the temperature influence can be approximately ignored.

\section{Conclusion}

A $\mathrm{pH}$ measuring application was designed in blue light therapy capsule. The sensor has a cylinder shape with $3.5 \mathrm{~mm}$ in diameter and $5.5 \mathrm{~mm}$ in length, and was integrated in the therapy capsule. It can detect the $\mathrm{pH}$ value of esophagus, gastric and intestinal tract, and automatically turn on or off the therapy module. By tracing the $\mathrm{pH}$ feedback information the capsule smartly adjust the system parameters. With the advancement in technology, increasing noninvasive and smart therapy capsules will be developed and becoming easier to use.

\section{Acknowledgements}

This work was supported by the National Natural Science Fund of China (No. 61571070), Science Fund of Chongqing China (No. cstc2012jjA10148 and No. KJ1400427). Corresponding author: Zhongyong Li, lizy@cqupt.edu.cn.

\section{References:}

[1] Kandulski A, Selgrad M, Malfertheiner P, Helicobacter pylori infection: a clinical overview, J. Dig Liver Dis. 40(2008) 619-26. 
[2] Hamblin MR, Viveiros J, Yang C, et al, Helicobacter pylori accumulates photoactive porphyrins and is killed by visible light, J. Antimicrob Agents Chem. 49(2005) 2822-7.

[3] Ganz RA, Viveiros J, Ahmad A, et al, Helicobacter pylori in patients can be killed by visible light, J. Lasers Surg Med. 36(2005):260-5.

[4] Lembo AJ, Ganz RA, Sheth S, et al, Treatment of Helicobacter pylori infection with intragastric violet light phototherapy-a pilot clinical trial, J. Lasers Surg Med. 41(2009) 337-44.

[5] Dai T, Gupta A, Murray CK, et al, Blue light for infectious diseases Propionibacterium acnes Helicobacter pylori and beyond? J. Drug Resist Updat. 15(2012) 223-36.

[6] Nakamura T, Terano A. Capsule endoscopy: past, present, and future J. J Gastro. 43(2008) 93-99.

[7] Than TD, Alici G, Zhou H, Li W. A review of localization systems for robotic endoscopic capsules, J. IEEE Trans Biomed Eng. 59(2012) 2387-99.

[8] Woods SP, Constandinou TG. Wireless capsule endoscope for targeted drug delivery: mechanics and design considerations, J. IEEE Trans Biomed Eng. 60(2013): 945-53.

[9] Shao Q, Liu H, Li HY, Yan YS. Miniature $\mathrm{pH}$ sensor for capsule endoscopy with composite diagnosis, J. Sensors. 2(2014) 339-42.

[10] Xu F, Yan GZ, Wang ZW, Jiang PP. Continuous accurate $\mathrm{pH}$ measurements of human GI tract using a digital pH-ISFET sensor inside a wireless capsule, J. Measurement. 64(2015) 49-56.

[11] Sehyuk Y, Doyoung J. Magnetic mechanical capsule robot for multiple locomotion mechanisms, J. International Journal of Control, Automation and Systems. 12(2014) 383-89.

[12] Li JN, Liu CL, Tao XH. Clinical utility and tolerability of JSPH-1 wireless esophageal $\mathrm{pH}$ monitoring system, J. BMC Gastroenterology. 15(2013): 10.

[13] Yamasue K, Hagiwara H, Tochikubo O, et al, Measurement of core body temperature by an ingestible capsule sensor and evaluation of its wireless communication performance, J. Advanced Biomedical Engineering. 1(2012) 9-15.

[14] Taylor NA, Tipton MJ, Kenny GP, Considerations for the measurement of core, skin and mean body temperatures, J. J Thermal Biology. 46(2014) 72-101. 